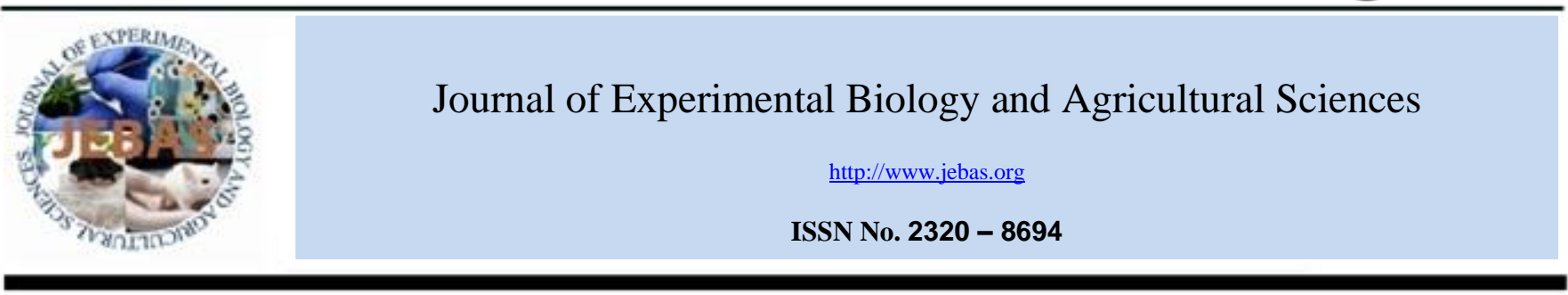

\title{
EFFECTS OF PREGNANCY AND DISEASE STRESS ON THE ANTIOXIDATIVE CAPACITY OF SHEEP AND GOAT
}

\section{Firas Mahmoud faleh Hayajneh*, Anas Abdelqader and Rabie AH Irshaid}

Department of animal production, Faculty of agriculture, Jordan University

Received - January 14, 2016; Revision - February 25, 2016; Accepted - October 01, 2016

Available Online - October 07, 2016

DOI: http://dx.doi.org/10.18006/2016.4(5S).605.609

\section{KEYWORDS}

Sheep

Goat

Pregnancy

Disease

Stress

Antioxidant

ABSTRACT

Sheep and goat undergoes various stresses throughout their life cycle, among various causes of these stresses pregnancy and diseases are the most common one which widely affected these two ruminants. The aim of this study was to investigate the effect of pregnancy and disease stress on antioxidative capacity of the sheep and goat, which in turn screens the total health status of the animal under study. Forty goat and sheep females (20 each) in two groups viz 15 diseased \& pregnant and 5 healthy females without pregnancy and diseases (control) were investigated for variations in the antioxidative capacity. Result of study revealed that acw value (the water soluble antioxidative capacity) was reported lowest in pregnant sheep $(5.75 \mathrm{mg} / \mathrm{l})$, whereas this value was reported highest in the control group $(7.08 \mathrm{mg} / \mathrm{l})$ which concluded that stress caused by pregnancy or disease reduced the antioxidative capacity of goat and sheep as compared the control group. Similar trends were reported in the goat also.
\end{abstract}

Free radical
* Corresponding author

E-mail: f_hayajneh@ju.edu.jo (Firas Mahmoud faleh Hayajneh)

Peer review under responsibility of Journal of Experimental Biology and Agricultural Sciences.

Production and Hosting by Horizon Publisher India [HPI] (http://www.horizonpublisherindia.in/).

All rights reserved.
All the article published by Journal of Experimental Biology and Agricultural Sciences is licensed under a Creative Commons Attribution-NonCommercial 4.0 International License Based on a work at www.jebas.org.

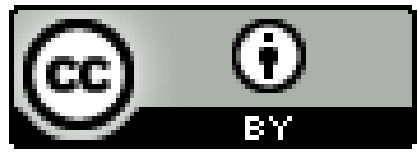




\section{Introduction}

Reactive oxygen species (ROS) are highly reactive chemical species which containing oxygen molecules such as hydroxyl radical, superoxide, peroxide and singlet oxygen (Kohen \& Gati, 2000; Hayyan et al., 2016). Biologically these molecules are continuously generated inside the animal body as a byproduct of the normal metabolism of oxygen but some time consequence of exposure to exogenous environmental chemicals such as UV, heat or by some endogenous metabolic processes such as involving redox enzymes or by some natural bio-energetic electrontransfer rate of ROS synthesis increased dramatically, which may caused severe losses or destruction to the cell structure (Devasagayam et al., 2004; Sreelatha \& Padma, 2009). Under normal circumstances, this generated ROS can be detoxified by the antioxidants present in animal body and there is equilibrium between the ROS generated and the antioxidants present. However, overproduction of ROS and/or inadequate antioxidant defence may hamper this equilibrium which favoring the ROS upsurge that culminates in oxidative stress (Kohen \& Gati, 2000; Kamiluglu et al., 2006). Oxidative damage is associated with formation of free radical; this overproduction of free radical or ROS may caused various health issues such as damage to cell membrane, damage to DNA, cardiovascular diseases, heart attack and some time it may cause cancer too (Conner et al., 2002; Rada \& Leto, 2008; Giannenas et al., 2009; Brooker, 2011).

According to Puppel et al. (2013) storage of free radicals have a crucial role in the development of over 100 diseases affecting all major organs. Tightly controlled ROS generation appears to be one of the central elements in the mechanisms involved in cell function, growth, differentiation and death (Valko et al., 2007). Maintaining a physiological equilibrium between intracellular antioxidants levels and production of reactive oxygen species (ROS) is crucial for the survival of the organisms (Garrel et al., 2010).

Animal body has various mechanisms to counteract oxidative stress, production of antioxidants are most common one. Antioxidants are the substances that inhibit the damaging effect of oxidation caused by free radicals. These antioxidants create a barrier against free radial damage that results in decaying process of oxidation. These antioxidant substances either produced naturally (endogenous antioxidants), or externally supplied through foods (exogenous antioxidants). These endogenous and exogenous antioxidants work as "free radical scavengers" by preventing and repairing damages caused by ROS and RNS, and therefore can enhance the immune defense and lower the risk of cancer and degenerative diseases. Superoxide dismutase, Catalase, Glutathione systems, butylated hydroxytoluene and butylated hydroxyanisole are the some common synthetic exogenous antioxidatant substances which reduced the level of ROS damage. While, Vitamin E ( $\alpha$ tocopherol), Vitamin C (Ascorbic acid), Beta-carotene, Lycopene, Selenium, Glutathione, Melatonin, Flavonoids, Uric acid, Omega-3 and omega- 6 fatty acids are the some endogenous which are recently used as supplements for the prevention or treatment of some chronic and degenerative diseases (Frei, 1997; Parthasarathy et al., 1999; Valko et al., 2005; Pham-Huy et al., 2008; Lobo et al., 2010; Sarma et al., 2010; Fiedor \& Burda, 2014).

Lipid peroxidation is a well-established mechanism of cellular injury, and is used as an indicator of oxidative stress in cell and tissues. Lipid peroxides derived from polyunsaturated fatty acids are unstable and can decompose to form a complex series of compounds which included reactive carbonyl compound such as malondialdehyde (MDA). Measurement of malondialdehyde is widely used as an indicator of lipid peroxidation, high levels of lipid peroxidation have been associated with a variety of chronic diseases in both human and animals (Romero et al., 1998). Further, Simsek et al. (2006) reported higher level of malondialdehyde in sheep infected with Dicrocoelium dendriticum. Moreover Sivakumar et al. (2010) also suggested that animals supplemented by antioxidants reduced the level of malondialdehyde in goat's serium which shows oxidative stress.

Pregnancy is mostly associated with metabolic rate which favor the developed of oxidative stress. According to Casanueva \& Viteri (2003) these oxidative stresses reached to the peaks by the second trimester of pregnancy and it may cause the death of fetus in the absence of antioxidant. Further, Fialová et al. (2006) reported higher level AOPPs (advanced oxidation protein products), CRP (C-reactive protein) and ACA (anticardiolipin antibodies) and $\mathrm{IgG}$ in the 1st and 2nd trimesters which reflect a maternal response to inflammatory and oxidative stress in pregnant women. Similarly Toescu et al. (2002) reported that last trimester of pregnancy was associated with the formation of susceptible, oxidisable particles (high LDL score) and an increase in oxidative damage and this may increase risk of cardiovascular disease. During pregnancy or diseased condition level of ROS increased and it can be prevent by the application of vitamin A and beta carotene (Kamiluglu et al., 2006). Most of the studies related to the effect of pregnancy and disease stress on antioxidant level are conducted on lower animals such as mice or rabbit and on human cells but information regarding the effect of these studies on ruminants are not much available, therefore, present study have been carried out to investigate the effect of pregnancy and disease stress on the level of antioxidant in goat and sheep.

\section{Materials and methods}

Study was conducted at the research laboratory of department of animal production, faculty of agriculture, Jordan University. Awassi breed of sheep and local breed of goat were used as experimental animal and author strictly followed ethical guideline proposed by university of Jordan which was based on the Helsinki Declaration of 1975. Forty goat and sheep has been selected (20 each) and divided in two groups viz 15 diseased and pregnant and 5 healthy (Control). Animals were 
diagnosed for clinical symptoms in clinic located at ministry of agriculture division and blood samples were taken from pregnant $\&$ disease and healthy animals. Age of sheep and goat was determined by oral herd records and dentition patterns. All the animals were fed on the recommend standard diet.

Blood samples were collected from jugular vein into sterile vials containing anti-coagulant heparin with the help of the trend veterinarian. Collected blood samples were marked properly and were taken in to the laboratory for rest study. These blood samples were centrifuged at 5000rpm for 5 minutes and kept under $-20 \mathrm{C}^{\mathrm{o}}$ until the testing time according to the analytical procedure.

Total water soluble antioxidant content was estimated spectrophotometrically by using a kit developed by cell biolabs (Cell Biolabs OxiSelect TAC Assay Kit) and following the method described by Hayajneh, (2015). Samples were compared with a known concentration of uric acid as a standard solution. MDA-reactive products were estimated by the using thiobarbituric acid method as described by Placer et al. (1966) and Nawito et al. (2016). Reaction of Thiobarbituric acid (TBA) and MDA form a Schiff base adduct under high temperature \& acidic conditions which is a chromogenic/ fluorescent product that can be easily measured by spectrophotometer. The statistical analyses of obtained results were performed by assessing of the mean values and standard deviations (SD) for each monitored group of sheep and goat. The significant differences among the mean values of studied parameters were carried out by one way analysis of variance (ANOVA).

\section{Results and Discussion}

Results shown in the table 1 indicated the effect of stress on the level of antioxidant, and pregnant and diseased animals show lower antioxidant (5.75 and $5.13 \mathrm{mg} / \mathrm{l}$ ) level as compared to healthy control (7.06 and 6.18) for sheep and goat respectively.

Further, higher level of Malondialdehyde $(0.53 \& 0.52 \mu \mathrm{mol} / \mathrm{l})$ was reported from the blood level of diseased and pregnant sheep and goat respectively as compared to healthy one. Results of present study are in the agreement with the findings of Hayajneh (2015) those who reported lower antioxidant activity in pregnant sheep blood samples.

Similar type of study was conducted by Nawito et al. (2016) and reported a significantly higher malondialdehyde (MDA) values in the blood of pregnant animals as compared to healthy non pregnant one. Further they reported a significant reduction in the activity of SOD. In this manner result of present study are in agreement with the findings of Nawito et al. (2016). Although they have reported some higher value of malondialdehyde and SOD as compared to the present study but this difference may be attribute to the difference in experimental conditions and diet composition. Further, Sordillo et al. (2007) established relationship between the physiological changes and the loss in the overall antioxidant potential in dairy cows during parturition.

Similarly, Konvičná et al. (2016) reported higher oxidative stress and lower antioxidant level in dairy cow just after the parturition. In this study these researchers reported significant changes between MDA and indicators of oxidative stress (SOD, GSH-Px, vitamin E) during parturition in dairy cows. Results of above said studies are in agreement with the findings of present study where improvement in MDM value and reduction in antioxidant potential was reported in the blood of pregnant goat and sheep.

Abdel Fattah et al. (2011) reported significantly higher malondialdehyde level and lower superoxide dismutase activity in alopecia areata compared to healthy control. Further they suggested higher lipid peroxidation and defective superoxide dismutase (SOD) activity in patient suffering from alopecia areata. Similarly, Adiga et al. (2007) measured the level of total cholesterol (TC), high-density lipoprotein cholesterol (HDL-C), atherogenic index (AI), malondialdehyde (MDA) were measured in 25 women with preeclampsia and 25 pregnant women and reported significantly higher level of MDA, TC and $\mathrm{Al}$ in preeclamptic patients as compared to the control group while the level of HDL-C was reduced in preeclamptic patients. Result of this study suggested that hypercholesterolemia leads to excessive lipid peroxidation. Coexistent diminution in antioxidant activity leads to an imbalance between prooxidants and antioxidants, resulting in oxidative stress.

Table 1 Effect of pregnancy and diseased stress on the concentration of water soluble antioxidant and malondialdehyde levels in the blood of sheep and goat.

\begin{tabular}{|llcc|c|} 
Animals & Nature & Number & $\begin{array}{c}\text { Concentration of water soluble } \\
\text { antioxidant }(\mathrm{mg} / \mathrm{l})^{*}\end{array}$ & $\begin{array}{c}\text { Concentration of Malondialdehyde } \\
(\mu \mathrm{mol} / \mathrm{l})^{*}\end{array}$ \\
\hline Sheep & Pregnant and Diseased & 15 & $5.75 \pm 0.709$ & $0.53 \pm 0.032$ \\
\cline { 2 - 5 } & Healthy (Control) & 05 & $7.08 \pm 0.454$ & $0.45 \pm 0.022$ \\
\hline Goat & Pregnant and Diseased & 15 & $5.13 \pm 0.540$ & $0.52 \pm 0.047$ \\
\cline { 2 - 5 } & Healthy (Control) & 05 & $6.26 \pm 0.779$ & $0.45 \pm 0.059$ \\
\hline
\end{tabular}

* Mean of selected animals; Value after \pm represents Standard Deviation 


\section{Conflict of interest}

Authors would hereby like to declare that there is no conflict of interests that could possibly arise.

\section{References}

Abdel Fattah NS, Ebrahim AA, El Okda ES (2011) Lipid peroxidation/antioxidant activity in patients with alopecia areata. Journal of the European Academy of Dermatology and Venereology 25: 403-408. DOI: $10.1111 / \mathrm{j} .1468-$ 3083.2010.03799.x.

Adiga U, D'souza V, Kamath A, Mangalore N (2007) Antioxidant Activity and Lipid Peroxidation in Preeclampsia. Journal of the Chinese Medical Association 70: 435-438. doi:10.1016/S1726-4901(08)70034-0.

Brooker RJ (2011) Genetics: analysis and principles 4th Ed. McGraw-Hill Science.

Casanueva E, Viteri FE (2003) Iron and oxidative stress in pregnancy. The journal of Nutrition 133: 1700S-1708S.

Conner GE, Salathe M, Forteza R (2002) Lactoperoxidase and hydrogen peroxide metabolism in the airway. American Journal of Respiratory and Critical Care Medicine 166 : S5761. doi:10.1164/rccm. 2206018.

Devasagayam T, Tilak JC, Boloor KK, Sane Ketaki S, Ghaskadbi Saroj S, Lele RD (2004) Free Radicals and Antioxidants in Human Health: Current Status and Future Prospects. Journal of Association of Physicians of India 52: 796.

Fialová L, Malbohan I, Kalousová M, Soukupová J, Krofta L, Stípek S, Zima T (2006) Oxidative stress and inflammation in pregnancy. Scandinavian Journal of Clinical and Laboratory Investigation 66:121-127.

Fiedor J, Burda K (2014) Potential Role of Carotenoids as Antioxidants in Human Health and Disease. Nutrients 6 : 466488. doi: $10.3390 /$ nu6020466.

Frei B (1997) Reactive oxygen species and antioxidant vitamins. Linus Pauling Institute. Oregon State University. Available on http://lpi.oregonstate.edu/f-w97/reactive.html access on April, 2014.

Garrel C, Fowler PA, Al-Gubory KH (2010) Developmental changes in antioxidant enzymatic defences against oxidative stress in sheep placentomes. Journal of Endocrinology 205: 107-116.

Giannenas I, Pappas IS, Mavridis S, Kontopidis G, Skoufos J, Kyriazakis I (2009) Performance and antioxidant status of broiler chickens supplemented with dried mushrooms
(Agaricus bisporus) in their diet. Poultry Science 89: 303-311. doi: 10.3382/ps.2009-00207.

Hayajneh FMF (2015) Variations in the water soluble antioxidative capacity in the blood of sheep. International Journal of Current Microbiology and Applied Sciences 4: 252255.

Hayyan M, Hashim MA, AlNashe IM (2016) Superoxide Ion: Generation and Chemical Implications. Chemical Reviews 116: 3029-3085. DOI: 10.1021/acs.chemrev.5b00407.

Kamiluglu NN, Beytut E, Aksakal M (2006) Alteration in antioxidant status and lipid peroxidation of sheep previously treated with vitamin a and $\beta$-carotene during breeding and periparturient period. Bulletin of the Veterinary Institute in Pulawy 50: 171-177.

Kohen R, Gati I. (2000) Skin low molecular weight antioxidants and their role in aging and in oxidative stress. Toxicology 148: 149-157. http://dx.doi.org/10.1016/S0300483X(00)00206-7.

Konvičná J , Vargová M , Paulíková I, Kováč G, Kostecká Z (2015) Oxidative stress and antioxidant status in dairy cows during prepartal and postpartal periods. Acta Veterinaria Brno 84: 133-140; doi:10.2754/avb201584020133.

Lobo V, Patil A, Phatak A, Chandra N (2010) Free radicals, antioxidants and functional foods: Impact on human health. Pharmacognosy Review 4: 118-126.

Nawito MF, Abd El Hameed AR, Sosa ASA, Mahmoud KGM (2016) mpact of pregnancy and nutrition on oxidant/antioxidant balance in sheep and goats reared in South Sinai, Egypt. Veterinary world 9 : 801-805. doi: 10.14202/vetworld.2016.801-805.

Parthasarathy S, Santanam N, Ramachandran S, Meilhac O (1999) Oxidants and antioxidants in atherogenesis: an appraisal. Journal of Lipid Research 40:2143-2157.

Pham-Huy LA, He H, Pham-Huy C (2008) Free Radicals, Antioxidants in Disease and Health. International Journal of Biomedical Sciences 4: 89-96.

Placer ZA, Cushmann L, Johnson BC (1966) Estimation of product of lipid peroxidation (malonyl dialdehyde) in biochemical systems. Analytical Biochemistry 16: 359-364. doi:10.1016/0003-2697(66)90167-9.

Puppel K, Nałęcz-Tarwacka T, Kuczyńska B, Gołębiewski M, Kordyasz M (2013) Effect of different fat supplements on the antioxidant capacity of cows milk. ArchivTierzucht 56: 178190.

Rada B, Leto TL (2008) Oxidative innate immune defenses by Nox/Duox family NADPH oxidases. In: Egesten A, Schmidt 
A, Herwald H (Eds), Trends in Innate Immunity. Contributions to Microbiology, Karger AG Basel 15: 164-187. doi:10.1159/000136357.

Romero FJ, Bosch-Morell F, Romero MJ, Jareno EJ, Romero B, Marin N, Roma J (1998) Lipid peroxidation products and antioxidants in human disease. Environmental Health Perspective 106: 1229-1234.

Sarma AD, Mallick AR, Ghosh AK (2010) Free Radicals and Their Role in Different Clinical Conditions: An Overview. International Journal of Pharma Sciences and Research 1 : 185192.

Simsek S, Yoce A, Utuk AE (2006) determination of serum malondialdehyde levels in sheep naturally infected with Dicrocoelium dendriticum. Fırat Üniversitesi Sağlık Bilimleri Dergisi $20: 217-220$.

Sivakumar AVN, Singh G, Varshney VP (2010) Antioxidants Supplementation on Acid Base Balance during Heat Stress in Goats. Asian-Australasian Journal of Animal Sciences 23: 1462 - 1468. doi: https://doi.org/10.5713/ajas.2010.90471.
Sordillo LM, O'Boyle N, Gandy JC, Corl CM, Hamilton E (2007) Shifts in thioredoxin reductase activity and oxidant status in mononuclear cells obtained from transition dairy cattle. Journal of Dairy Science 90: 1186-1192.

Sreelatha S, Padma PR (2009) Antioxidant Activity and Total Phenolic Content of Moringaoleifera Leaves in Two Stages of Maturity. Plant Foods for Human Nutrition 64: 303-311. DOI: 10.1007/s11130-009-0141-0.

Toescu V, Nuttall SL, Martin U, Kendall MJ, Dunne F (2002) Oxidative stress and normal pregnancy. Clinical Endocrinology $\quad 57: 609-613 . \quad$ DOI: $\quad 10.1046 /$ j.13652265.2002.01638.x.

Valko M, Leibfritz D, Moncol J, Cronin MT, Mazur M, Telser J (2007) Free radicals and antioxidants in normal physiological functions and human disease. International Journal of Biochemistry \& Cell Biology 39 : 44-84. http://dx.doi.org/10.1016/j.biocel.2006.07.001.

Valko M, Morris H, Cronin MTD (2005) Metals, toxicity and oxidative stress. Current Medical Chemistry12:1161-1208. DOI: $10.2174 / 0929867053764635$. 